\title{
Adaptive digital PID control of pressure process
}

\author{
Gediminas Liaučius, \\ Vytautas Kaminskas \\ Department of Systems Analysis, \\ Vytautas Magnus University, \\ Vileikos Str. 8, LT-44404 Kaunas \\ E-mail: g.liaucius@if.vdu.lt
}

In this paper the adaptive digital control of the pressure process based on PID (proportional-integral-derivative) controllers is investigated. A method for optimization of closed-loop parameters and the continuous-time sampling period of the control system is proposed. The adaptive PID control with optimization significantly improves the control quality of the pressure process, which is demonstrated experimentally.

Key words: pressure process, adaptive digital PID control, closed-loop parameters, sampling period, optimization

\section{INTRODUCTION}

The pressure process is a continuous-time process. Various physical nature continuous-time processes [1-5] are controlled by digital controllers. The methods based on the digital PID (proportional-integral-derivative) control are the most common for the control of continuous-time processes $[6,7]$. The selection of the optimal closed-loop parameters and the continuous-time sampling period for the digital PID control is very important. In this paper the adaptive digital PID control is investigated, where the main focus of attention is not just the on-line identification of the process, but also the determination of the optimal closedloop parameters and sampling period.

\section{THE PRESSURE PROCESS}

The scheme of the pressure process is demonstrated in Fig. 1 [8]. Such process exists in air conditioning and cooling systems.

The process consists of four main components: combined air inlet (No.1) and outlet (No.4) tanks, two air chambers (No.2) and two tubes (No.3) with balls (No.6) in them.

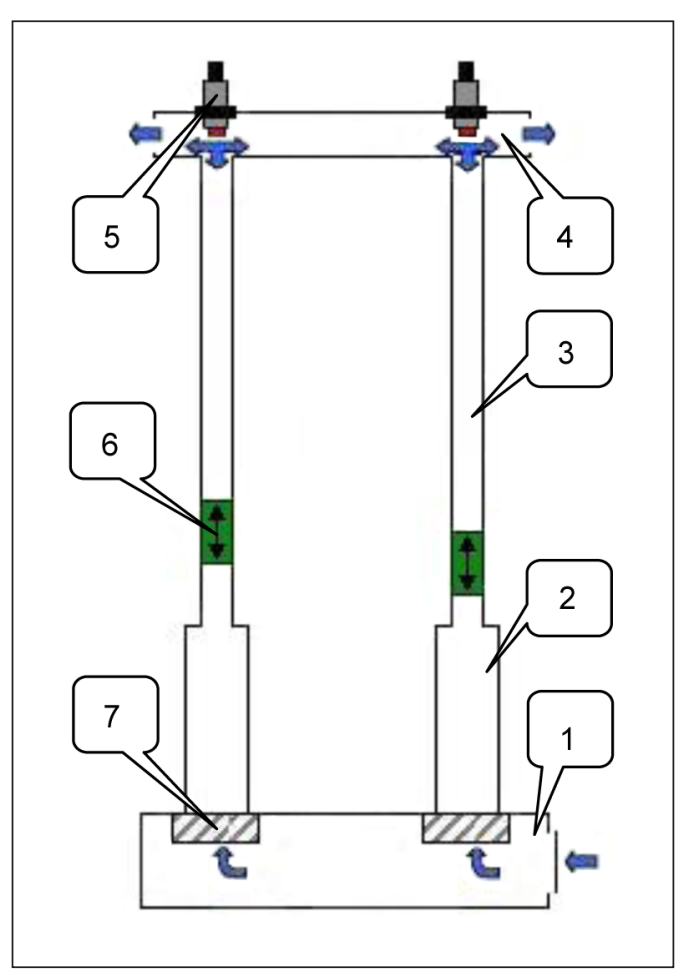

Fig. 1. The scheme of the pressure process 
The air from the inlet tank flows to air channels through air chambers and leaves the equipment through the upper outlet tank. The distance to balls is measured using ultrasound distance sensors (No. 5). The fans (No. 7) are used to create pressure in the air channels in order to lift the balls in tubes. The air chambers are utilized for the purpose to stabilize oscillations of the pressure in each tube. The momentum of the fan, the inductance of the fan motor, air turbulence in the tube leads to complex physics governing ball behaviour. Slightly different weights of the balls and the location of the air feeding vent additionally impact the behaviour of ball in the tubes.

Technical characteristics of the process are as follows: the volume of the air inlet tank is about $7000 \mathrm{~cm}^{3}$, the diameter of the air feeding valve is $7 \mathrm{~cm}$. The volume of each air chamber is about $1300 \mathrm{~cm}^{3}$. Each tube is $110 \mathrm{~cm}$ long with a diameter of $4 \mathrm{~cm}$. The volume of the air outlet tank is about $2900 \mathrm{~cm}^{3}$, the diameters of air outlet vents are $6.5 \mathrm{~cm}$. The weights of the balls for the first and for the second tube are $3.62 \mathrm{~g}$ and $3.58 \mathrm{~g}$, respectively. For each air chamber, two coupled Zalman PS80252H fans are utilized and Nivelco Microsonar UTP-212-4 ultrasound sensors are used for sensing the positions of the balls.

The control signals (inputs) of the process are the voltage values for each fan from the range between 0 and $10 \mathrm{~V}$. The intermediate values of voltage affect the power of the fan proportionately. The control responses (outputs) are the distances between the balls and the bottom of their tubes from the range between 20 and 90 in centimetres. The control problem is to regulate the speed of the fan supplying the air into the tube so as to keep the ball suspended at some predetermined level in the tube.

An industrial Beckhoff BK9000 programmable logic controller (PLC) is used for the realization of digital control. The PLC controller is configured and controlled by the TwinCat software.

\section{SELF-TUNING PID CONTROL WITH ON-LINE IDENTIFICATION}

The process mathematical model is required in order to design the digital self-tuning PID control with on-line identification. Each tube of the process is defined by discrete linear second order difference equations, i. e.:

$$
\begin{aligned}
& A^{(i)}\left(z^{-1}\right) y_{t}^{(i)}=B^{(i)}\left(z^{-1}\right) u_{t}^{(i)}+\zeta_{t}^{(i)}, \\
& B^{(i)}\left(z^{-1}\right)=b_{1}^{(i)} z^{-1}+b_{2}^{(i)} z^{-2} \\
& A^{(i)}\left(z^{-1}\right)=1+a_{1}^{(i)} z^{-1}+a_{2}^{(i)} z^{-2}
\end{aligned}
$$

where $A^{(i)}\left(z^{-1}\right), B^{(i)}\left(z^{-1}\right)$ are the model polynomials, $i=1,2$ is the number of the tube of the pressure process, $y_{t}^{(i)}=y^{(i)}\left(t T_{0}\right), u_{t}^{(i)}=u^{(i)}\left(t T_{0}\right)-$ output and input signals with the sampling period $T_{0}$ respectively, $\zeta_{t}^{(i)}$ is a white noise of the $i$ th tube with a zero mean and finite variance and $z^{-1}$ is the backward-shift operator.

The model parameters of the ith tube:

$$
\Theta^{(i) T}=\left[a_{1}^{(i)}, a_{2}^{(i)}, b_{1}^{(i)}, b_{2}^{(i)}\right]
$$

are unknown. On-line identification of model parameters of the $i$ th tube is performed by the modified recursive least squares algorithm with the forgetting factor $[7,8]$ :

$$
\begin{aligned}
& \hat{\Theta}_{t}^{(i)}=\left\{\begin{array}{cc}
\hat{\Theta}_{t-1}^{(i)}, & \text { if }\left|e_{t}^{(i)}\right| \leq \delta_{e}^{(i)} \text { or }\left|z_{j}^{(i)}\right|<1 \\
\hat{\Theta}_{t-1}^{(i)}+\frac{\mathrm{C}_{t}^{(i)} \varphi_{t-1}^{(i)}}{1+\eta_{t}^{(i)}} \hat{\varepsilon}_{t}^{(i)}, & \text { otherwise }
\end{array}\right. \\
& \hat{\Theta}_{t}^{(i) T}=\left[\hat{a}_{1}^{(i)}, \hat{a}_{2}^{(i)}, \hat{b}_{1}^{(i)}, \hat{b}_{2}^{(i)}\right], \\
& \varphi_{t-1}^{(i)}=\left[-y_{t-1}^{(i)},-y_{t-2}^{(i)}, u_{t-1}^{(i)}, u_{t-2}^{(i)}\right], \\
& \eta_{t}^{(i)}=\varphi_{t-1}^{(i)} \mathrm{C}_{t}^{T} \varphi_{t-1}^{(i)}, \\
& \hat{\varepsilon}_{t}^{(i)}=y_{t}^{(i)}-\hat{\Theta}_{t-1}^{(i)} \varphi_{t-1}^{(i)}, \\
& \mathrm{C}_{t}^{(i)}=\left\{\begin{array}{cc}
\mathrm{C}_{t-1}^{(i)}-\frac{\mathrm{C}_{t-1}^{(i)} \varphi_{t-1}^{(i)} \varphi_{t-1}^{(i)} \mathrm{C}_{t-1}^{(i)}}{\lambda^{-1}{ }_{t}^{(i)}+\eta_{t}^{(i)}}, & \text { if } \eta_{t}^{(i)}>0 \\
\mathrm{C}_{t-1}^{(i)}, & \text { if } \eta_{t}^{(i)}=0
\end{array}\right. \\
& \lambda_{t}^{(i)}=\varphi^{(i)}-\frac{1-\varphi^{(i)}}{\eta_{t-1}^{(i)}}, \\
& e_{t}^{(i)}=y_{t}^{(i)^{*}}-y_{t}^{(i)},
\end{aligned}
$$

where $\hat{\Theta}^{(i)}$ is the estimated vector of model parameters, $c^{(i)}$ is a square covariance matrix, $\varphi^{(i)}$ is a data vector, $\hat{\varepsilon}^{(i)}$ is the prediction error, $\varphi^{(i)}$ is the forgetting factor, $\eta^{(i)} \lambda^{(i)}$ are auxiliary variables, $e_{t}^{(i)}$ is the control error, $\delta_{t}^{(i)}$ is a constant that defines the admissible interval of the control error $e_{t}^{(i)}, z_{j}^{(i)}, j=1,2$ are the roots of polynomial $\hat{A}_{t}^{(i)}\left(z^{-1}\right)$ and $y_{t}^{(i)^{*}}$ is a reference signal (predermined level) of the $i$ th tube.

Applying the on-line identification algorithm (5), the estimates of model parameters are updated only if the value of $e_{t}^{(i)}$ is outside the admissible interval defined by $\delta_{e}^{(i)}$ and the model after its last estimation remains stable.

At the design of the digital self-tuning PID control, the results of the on-line identification of models are used. The most common types of the digital self-tuning PID control with the on-line identification are the digital self-tuning PID-A and the digital self-tuning PID-B controls [7]. The results of the experimental analysis showed that the digital self-tuning PID-B control suited better than the digital self-tuning PID-A control for the pressure process [9]. The PID-B controller is defined as follows [10]: 


$$
\begin{aligned}
& S^{(i)}\left(z^{-1}\right) u_{t}^{(i)}=\beta^{(i)} e_{t}^{(i)}-R^{(i)}\left(z^{-1}\right) y_{t}^{(i)}, \\
& S^{(i)}\left(z^{-1}\right)=\left(1-z^{-1}\right)\left(1+\gamma^{(i)} z^{-1}\right), \\
& R^{(i)}\left(z^{-1}\right)=r_{0}^{(i)}\left(1-z^{-1}\right)\left(1-\frac{r_{2}^{(i)}}{r_{0}^{(i)}} z^{-1}\right)= \\
& =r_{0}^{(i)}-\left(r_{0}^{(i)}+r_{2}^{(i)}\right) z^{-1}+r_{2}^{(i)} z^{-2},
\end{aligned}
$$

where $S^{(i)}\left(z^{-1}\right), R^{(i)}\left(z^{-1}\right)$ are the polynomials of the controller and $\beta^{(i)}, \gamma^{(i)}, \mathrm{r}_{0}{ }^{(i)}, \mathrm{r}_{2}{ }^{(i)}$ are the parameters of the PID-B controller of the ith tube.

In order to determine the PID-B controller parameters the desired closed-loop characteristic polynomial for the $i$ th tube is formulated as

$$
D^{(i)}\left(z^{-1}\right)=1+\sum_{j=1}^{n_{d}} d_{j}^{(i)} z^{-j}, n_{d} \leq 4,
$$

the coefficients of which are determined by converting the continuous-time second order system

$$
s^{2}+2 \zeta \omega s+\omega^{2}=0
$$

by the discrete Laplace transformation [7]:

$$
\begin{aligned}
& d_{1}^{(i)}= \begin{cases}-2 \exp \left(-\zeta \omega T_{0}\right) \cos \left(\omega T_{0} \sqrt{1-\zeta^{2}}\right), & \text { if } \zeta \leq 1 \\
-2 \exp \left(-\zeta \omega T_{0}\right) \cosh \left(\omega T_{0} \sqrt{\zeta^{2}-1}\right), & \text { if } \zeta>1\end{cases} \\
& d_{2}^{(i)}=\exp \left(-2 \zeta \omega T_{0}\right), \\
& d_{3}^{(i)}=d_{4}^{(i)}=0,
\end{aligned}
$$

where $\omega$ is the natural frequency of oscillation, $\zeta$ is the damping factor. The PID-B controller parameters of the $i$ th tube are calculated as follows [7]:

$$
\begin{aligned}
& \beta^{(i)}=\frac{1}{\hat{b}_{1}^{(i)}}\left(d_{1}^{(i)}+1-\hat{a}_{1}^{(i)}-\gamma^{(i)}-\hat{b}_{1}^{(i)} r_{0}^{(i)}\right), \\
& \gamma^{(i)}=r_{2}^{(i)} \frac{\hat{b}_{2}^{(i)}}{\hat{a}_{2}^{(i)}}, \\
& r_{0}^{(i)}=r_{2}^{(i)}\left(\frac{\hat{b}_{1}^{(i)}}{\hat{b}_{2}^{(i)}}-\frac{\hat{a}_{1}^{(i)}}{\hat{a}_{2}^{(i)}}\right)-\frac{\hat{a}_{2}^{(i)}}{\hat{b}_{2}^{(i)}}, \\
& r_{2}^{(i)}=\hat{a}_{2}^{(i)} \hat{b}_{2}^{(i)}\left[\hat{a}_{1}^{(i)}\left(\hat{b}_{1}^{(i)}+\hat{b}_{2}^{(i)}\right)+\hat{b}_{1}^{(i)}\left(d_{2}^{(i)}-\hat{a}_{2}^{(i)}\right)\right], \\
& r_{2}^{\prime(i)}=-\hat{a}_{2}^{(i)}\left[\left(\hat{b}_{2}^{(i)}\right)^{2}\left(d_{1}^{(i)}+1\right)+\hat{a}_{2}^{(i)}\left(\hat{b}_{1}^{(i)}\right)^{2}\right], \\
& r_{2}^{(i)}=\frac{r_{2}^{(i)}+r_{2}^{\prime(i)}}{\left[\hat{b}_{1}^{(i)}+\hat{b}_{2}^{(i)}\right]\left[\hat{a}_{1}^{(i)} \hat{b}_{1}^{(i)} \hat{b}_{2}^{(i)}-\hat{a}_{2}^{(i)}\left(\hat{b}_{1}^{(i)}\right)^{2}-\left(\hat{b}_{2}^{(i)}\right)^{2}\right]} .
\end{aligned}
$$

\section{CLOSED-LOOP OPTIMIZATION}

The control quality of the pressure process can be defined by the criterion [9]:

$$
\begin{aligned}
& Q\left(\omega, \zeta, T_{0}\right)=\frac{1}{N} \sum_{t=1}^{N}\left\{\left[\left(y_{t}^{(1)}-y_{t}^{(1)}\right)^{2}+\left(y_{t}^{(2)^{*}}-y_{t}^{(2)}\right)^{2}\right]+\right. \\
& \left.+\rho\left[\left(u_{t}^{(1)}-u_{t-1}^{(1)}\right)^{2}+\left(u_{t}^{(2)}-u_{t-1}^{(2)}\right)^{2}\right]\right\},
\end{aligned}
$$

where $N$ is the number of observations, $\rho \geq 0$ is the weight coefficient. The control criterion consists of two components: the first component estimates the variance of the control error of each tube, the second one characterizes the variance of control signal change of each tube.

The required output of the control system with digital self-tuning PID-B controllers can be achieved by appropriate selection of the parameters $\omega, \zeta, T_{0}$. In such a case, it is reasonable to find the parameters $\omega^{*}, \zeta^{*}, T_{0}^{*}$ that minimize the criterion (25):

$$
\omega^{*}, \zeta^{*}, T_{0}^{*}: Q\left(\omega, \zeta, T_{0}\right) \rightarrow \min _{\omega, \zeta, T_{0}}
$$

The optimization problem is solved as follows. The optimal sampling period $T_{0}^{*}$ is obtained by

$$
\begin{aligned}
& T_{0}^{*}: J_{T}\left(T_{0}\right) \rightarrow \min _{T_{0}}, \\
& J_{T}\left(T_{0}\right)=\min _{\omega, \zeta}\left(Q\left(\omega, \zeta, T_{0}\right)\right) .
\end{aligned}
$$
ed by

The optimal closed-loop parameters $\omega^{*}, \zeta^{*}$ are obtain-

$$
\omega^{*}, \zeta^{*}: Q\left(\omega, \zeta, T_{0}^{*}\right) \rightarrow \underset{\omega, \zeta}{\min }
$$

In order to solve the optimization problem of (27), a technique of one-dimensional search is used. The most popular algorithms of this technique are golden section and quadratic interpolation [11]. The results of the experimental analysis [12] showed that the golden section algorithm for the pressure process is more effective.

The golden section algorithm is related with an initial uncertainty interval

$$
\left[T_{01}, T_{04}\right] \subset\left[0, T_{0 \max }\right],
$$

reduction to the interval

$$
\left[T_{01}^{(L)}, T_{04}^{(L)}\right], \quad \text { if } T_{04}^{(L)}-T_{01}^{(L)} \leq \Delta T_{0},
$$

where its length is not longer than the desired $\Delta T_{0}$, and with a function (28) minimum inside. For this purpose, two new values of the sampling period $T_{0}$ are chosen by

$$
\begin{aligned}
& T_{02}^{(l)}=0.382 \times\left(T_{04}^{(l)}-T_{01}^{(l)}\right)+T_{01}^{(l)} \\
& T_{03}^{(l)}=0.618 \times\left(T_{04}^{(l)}-T_{01}^{(l)}\right)+T_{01}^{(l)}
\end{aligned}, l=1,2, \ldots, L
$$


in the search procedure and a new uncertainty interval is then defined by the rule:

$$
\begin{aligned}
& {\left[T_{01}^{(l+1)}, T_{04}^{(l+1)}\right]=\left[T_{01}^{(l)}, T_{03}^{(l)}\right], \quad \text { if } J_{T}\left(T_{02}^{(l)}\right)<J_{T}\left(T_{03}^{(l)}\right)} \\
& {\left[T_{01}^{(l+1)}, T_{04}^{(l+1)}\right]=\left[T_{02}^{(l)}, T_{04}^{(l)}\right] .}
\end{aligned}
$$

Then the optimal sampling period $T_{0}^{*}$ is obtained by

$$
T_{0}^{*}=\left\{\begin{array}{lc}
T_{02}^{(L-1)}, & \text { if } J_{T}\left(T_{02}^{(L-1)}\right)<J_{T}\left(T_{03}^{(L-1)}\right) \\
T_{03}^{(L-1)} . & \text { otherwise }
\end{array}\right.
$$

The sub-component optimization methodology [11] is applied to solve the optimization problem of (28):

$$
\begin{aligned}
& \omega^{(j)}: J_{\omega}(\omega) \rightarrow \min _{\omega} j=1,2, \ldots, \\
& \zeta^{(j)}: J_{\zeta}(\zeta) \rightarrow \min _{\zeta} j=
\end{aligned}
$$

where

$$
\begin{aligned}
& J_{\omega}(\omega)=Q\left(\omega, \zeta^{(j-1)}, T_{0}^{(l+1)}\right) \\
& J_{\zeta}(\zeta)=Q\left(\omega^{(j)}, \zeta, T_{0}^{(l+1)}\right),
\end{aligned}
$$

where $T_{0}^{(l+1)}$ is a $T_{0}$ value, obtained by the golden section algorithm, where the new value of (28) must be calculated, i. e.:

$$
T_{0}^{(l+1)}=\left\{\begin{array}{lc}
T_{02}^{(l+1)}, & \text { if } J_{T}\left(T_{02}^{(l)}\right)<J_{T}\left(T_{03}^{(l)}\right) \\
T_{03}^{(l+1)} . & \text { otherwise }
\end{array}\right.
$$

The scheme of the adaptive digital PID control pressure process is depicted in Fig. 2.

\section{EXPERIMENTAL ANALYSIS}

The experimental analysis has been performed for 3 cases: adaptive digital PID control ((5), (13), (26)), digital selftuning PID control with non-optimal closed-loop parameters and optimal sampling period and digital self-tuning PID control with optimal closed-loop parameters and nonoptimal sampling period.

The predefined conditions of the experimental analysis are as follows: the initial uncertainty intervals of closedloop parameters $\omega \in[0.02,1.0], \zeta \in[0.02,2.0]$ and the sampling period $T_{0} \in[0.04,0.2]$ have been selected with $\Delta T_{0}=0.06$. The optimization (35) is started with an initial damping factor $\zeta^{(0)}=1.0$.

The searches of the sampling period and closed-loop parameters by the golden section algorithm are depicted in Fig. 3 and Fig. 4.

Fig. 3 demonstrates that the optimal sampling period obtained by the golden section algorithm is with $T_{0}^{*}=0.08 \mathrm{sec}$ and Fig. 4 depicts the search of closed-loop parameters with that value of the sampling period. It should be noticed that the criterion with the fixed sampling period to its optimal value is optimized within 3 steps of the sub-component search procedure by the golden section algorithm thus it is necessary to find 28 criterion values.

The optimization results by the golden section algorithm have shown that the optimal closed-loop parameters and the optimal sampling period are $\omega^{*}=0.146, \zeta^{*}=0.92$, $T_{0}^{*}=0.08 \mathrm{sec}$ with the minimal criterion value $Q^{*}=83.17$.

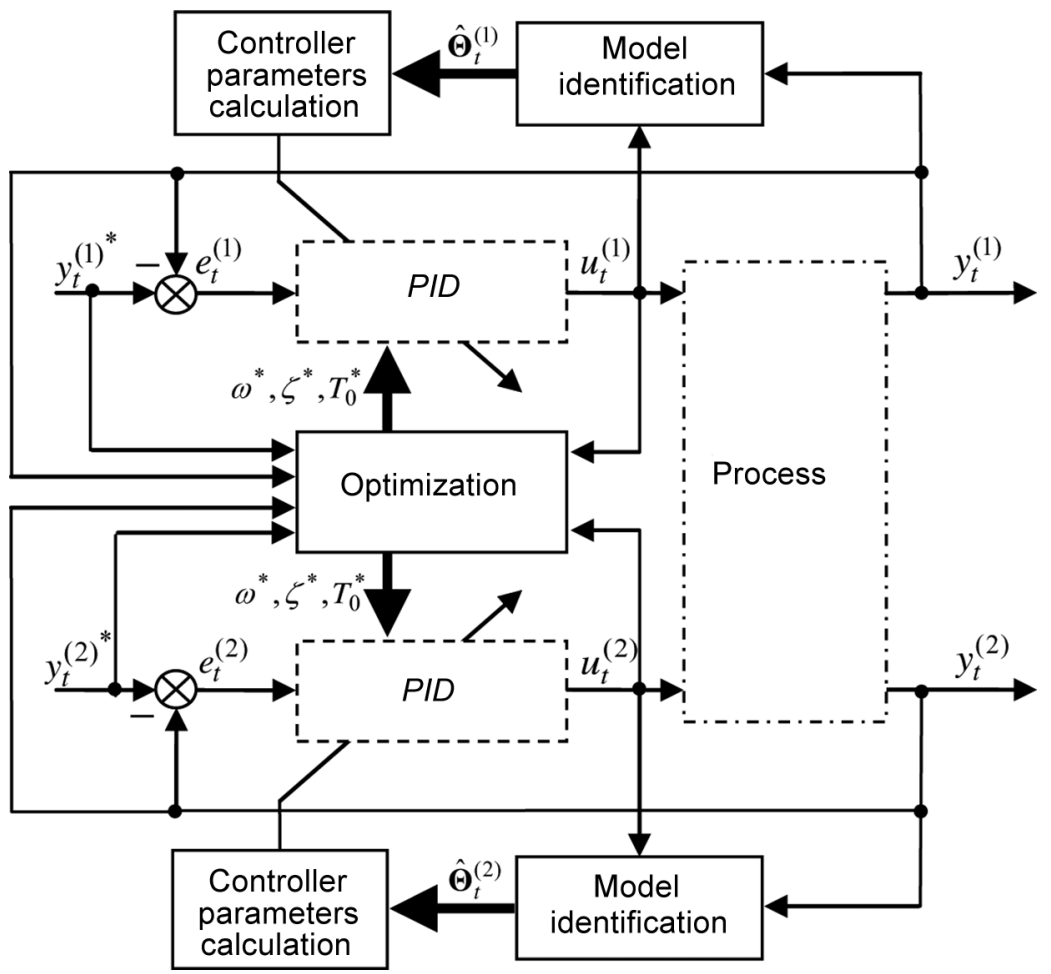

Fig. 2. The scheme of the adaptive digital PID control of the pressure process 


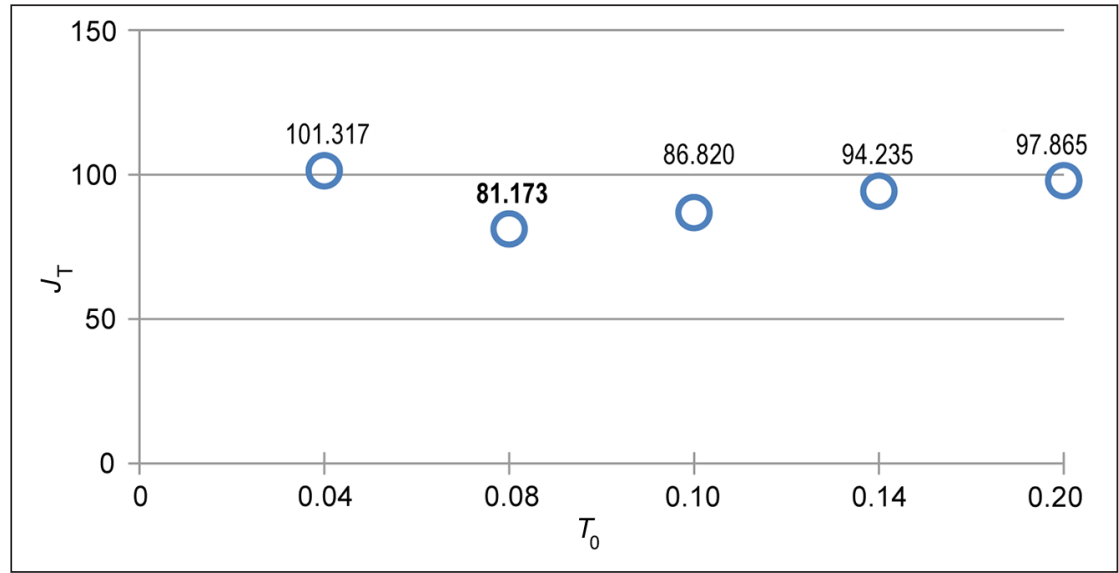

Fig. 3. Search of the sampling period by the golden section algorithm

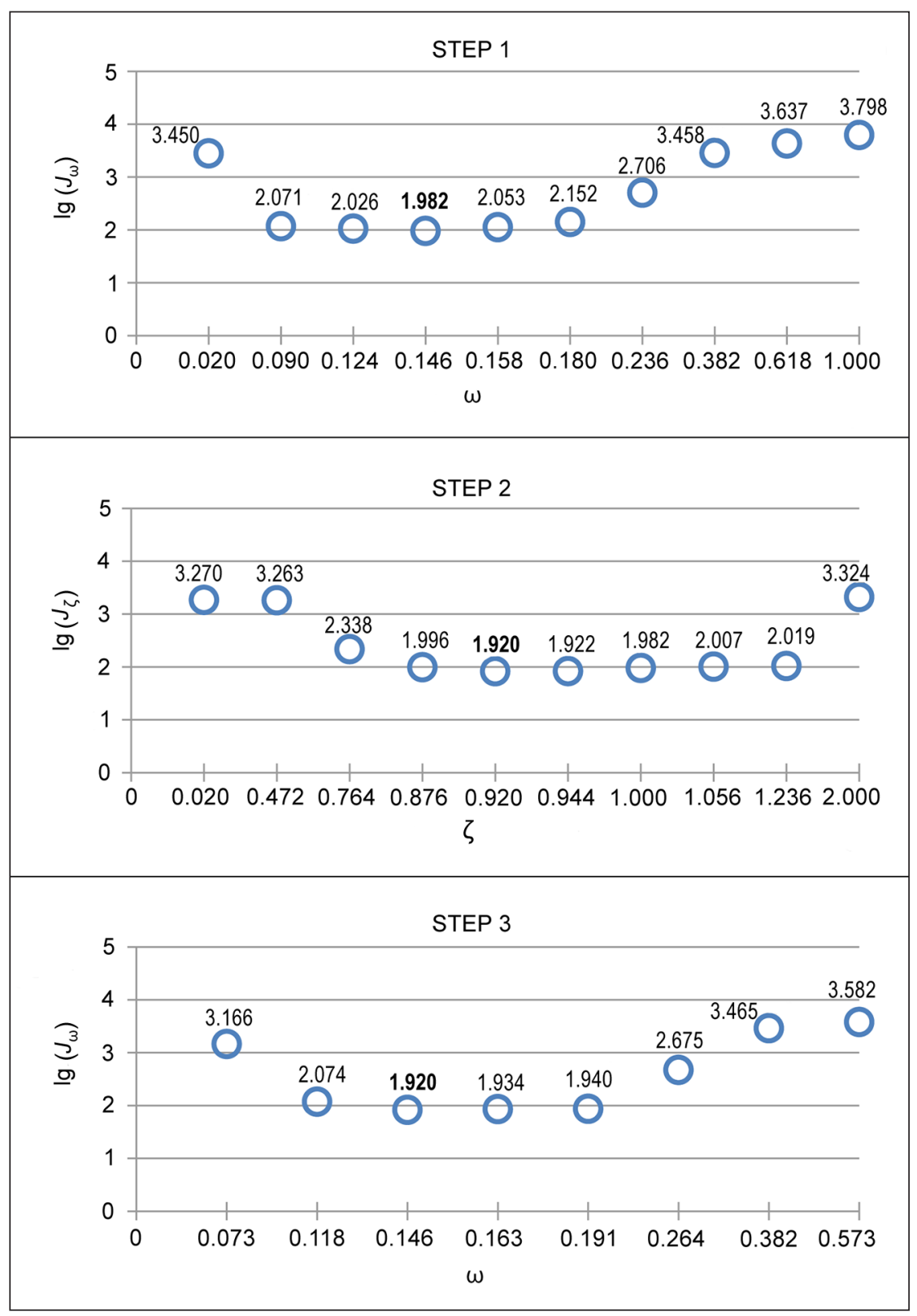

Fig. 4. Search of closed-loop parameters by the golden section algorithm with the optimal sampling period $T_{0}^{*}=0.08 \mathrm{sec}$
The control performance of the adaptive digital PID control of the pressure process with the optimal closed-loop parameters and the optimal sampling period is demonstrated in Fig. 5.

The control quality of the digital self-tuning PID control of the pressure process with the nonoptimal damping factor with the criterion value $Q=217.97$ is illustrated in Fig. 6.

It is seen from the graph that the control performance of the pressure process is poor, especially of the second tube - the output signal does not settle in a certain time and the control signal oscillates with a relatively high amplitude.

The control quality of the selftuning PID control of the pressure process with the non-optimal natural frequency of oscillation with the criterion value $Q=473.686$ is illustrated in Fig. 7.

In this case (Fig. 7) the value of natural frequency of oscillation $\omega$ is increased approximately twice from its optimal value, this leads to even worse control quality of both tubes of the pressure process as compared to the previous case (Fig. 6).

The control quality of the selftuning PID control of the pressure process with the non-optimal sampling period with the criterion value $Q=117.64$ is illustrated in Fig. 8.

Shifting the sampling period approximately twice from its optimal value (Fig. 8), the control performance of the pressure process is increased as compared to the cases with non-optimal closedloop parameters (Fig. 6 and Fig. 7), but also worse as compared to Fig. 5. Figure 8 confirms the fact that the selection of closed-loop parameters has more impact on the control quality of the pressure process than the selection of the sampling period. 


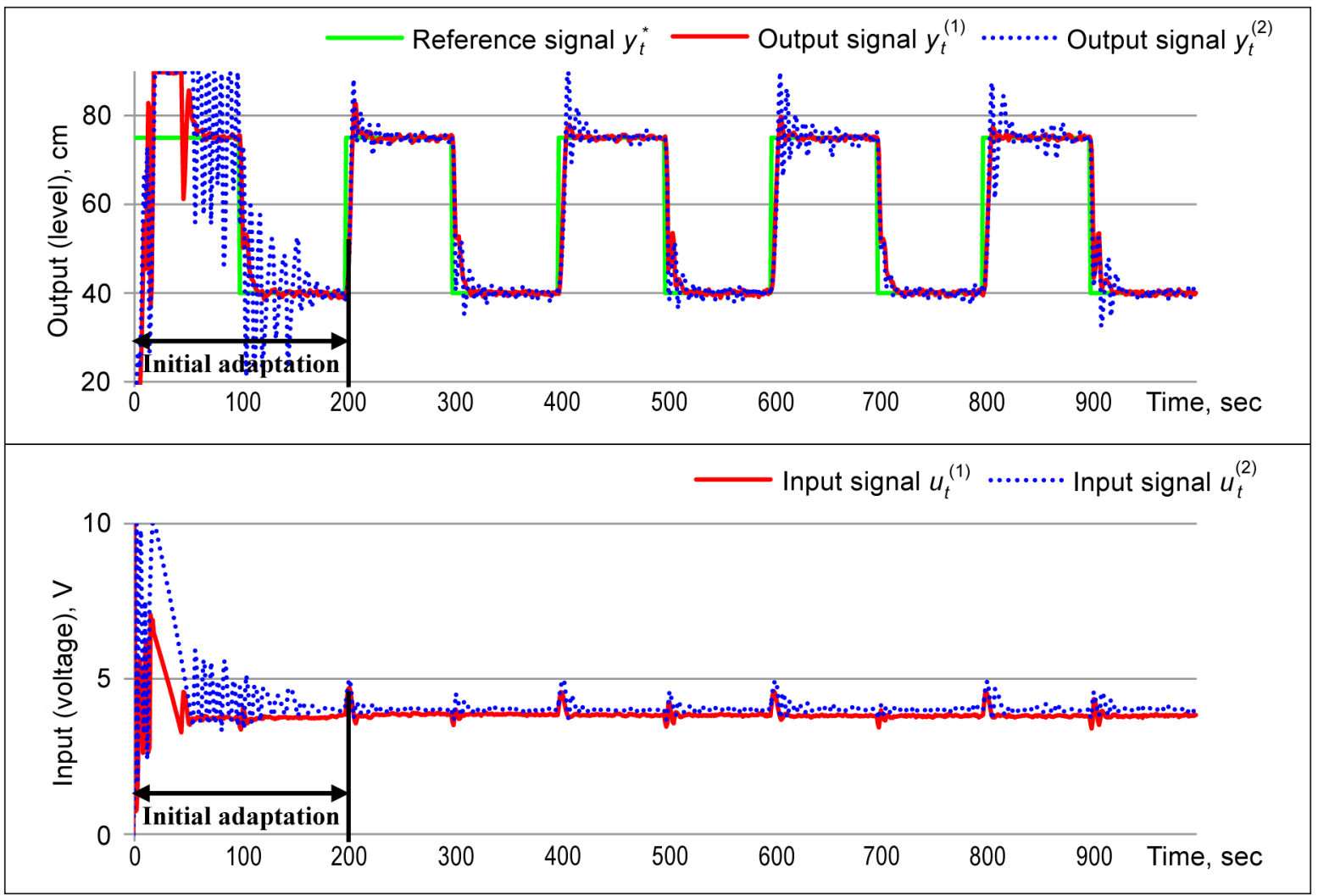

Fig. 5. Control performance of the adaptive digital PID control of the pressure process with the optimal closed-loop parameters and the optimal sampling period $-\omega^{*}=0.146, \zeta^{*}=0.92, I_{0}^{*}=0.08 \mathrm{sec}$

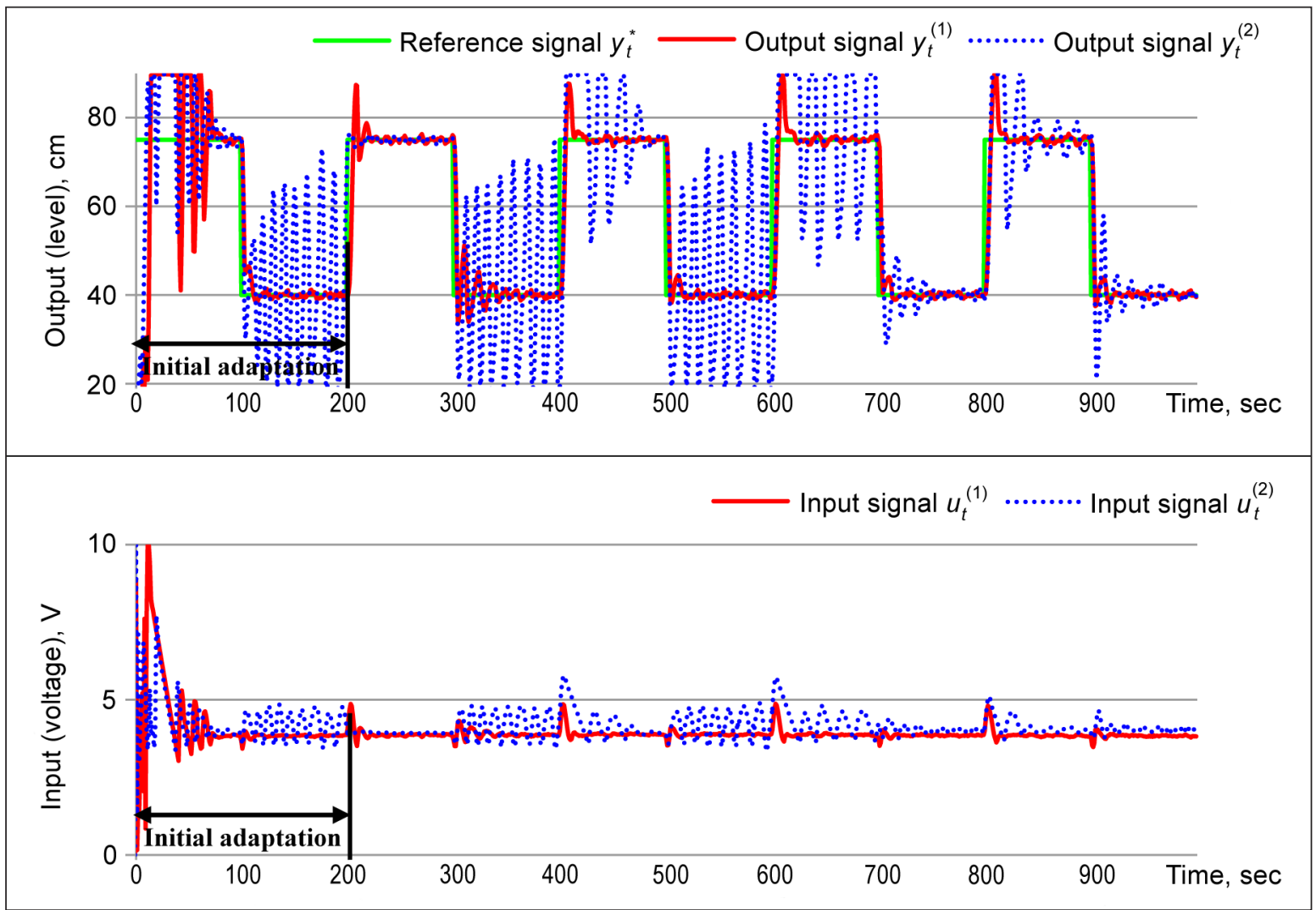

Fig. 6. Control performance of the digital self-tuning PID control of the pressure process with the non-optimal damping factor $-\omega^{*}=0.146, \zeta=0.764, T_{0}^{*}=0.08 \mathrm{sec}$ 


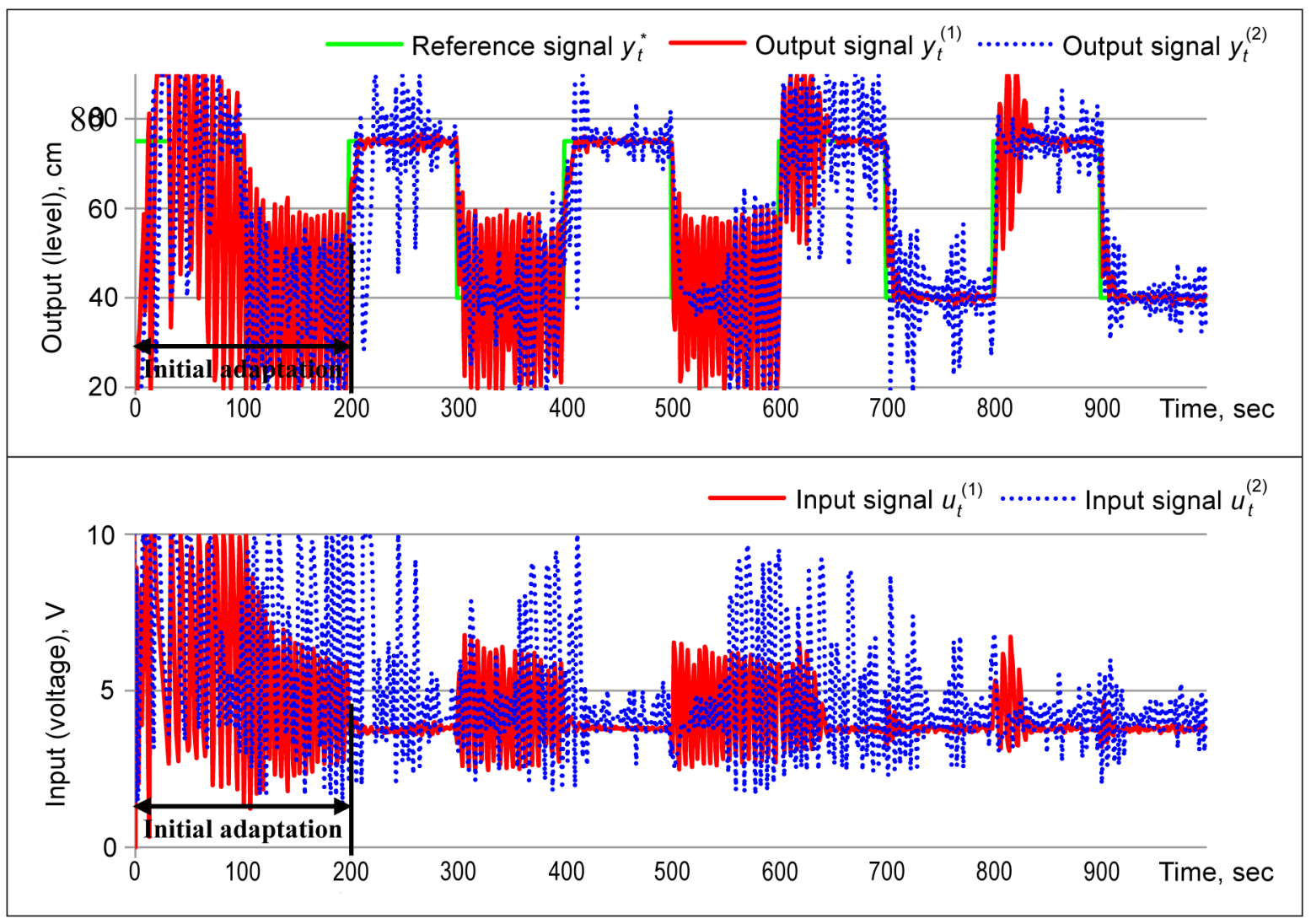

Fig. 7. Control performance of the digital self-tuning PID control of the pressure process with the non-optimal natural frequency of oscillation $-\omega=0.25, \zeta^{*}=0.92, T_{0}^{*}=0.08 \mathrm{sec}$

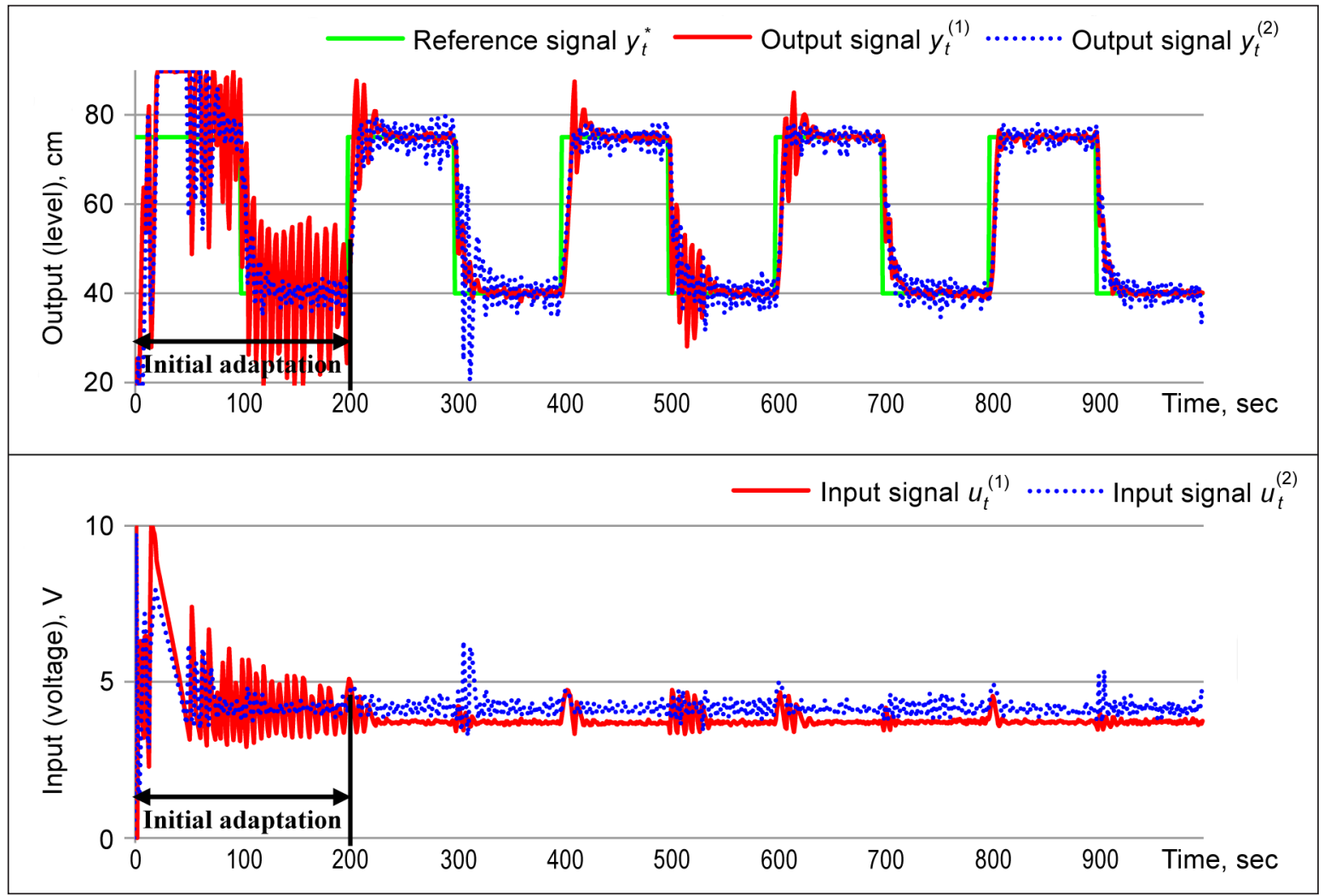

Fig. 8. Control performance of the digital self-tuning PID control of the pressure process with non-optimal sampling period $-\omega^{*}=0.146, \zeta^{*}=0.92, T_{0}=0.14 \mathrm{sec}$ 


\section{CONCLUSIONS}

The proposed adaptive digital PID control with the on-line identification and optimization of closed-loop parameters and the sampling period significantly improves the control quality of the pressure process. It was experimentally proved that the closed-loop parameters have more impact on the control quality of the pressure process than the sampling period. It was proved that the multidimensional optimization problem of the closed-loop parameters and the sampling period by the subcomponent search methodology can be divided into rather simple minimization problems of one-variable functions. The golden section algorithm is effective for the minimization of one-variable functions.

Received 1 August 2012 Accepted 25 August 2012

\section{References}

1. Ak A. G., Cansever G., Delibasi A. Robot trajectory tracking with adaptive RBFNN-based fuzzy sliding mode control. Information Technology and Control. 2011. Vol. 40. No. 2. P. 151-156.

2. Galvanauskas V. Adaptive $\mathrm{pH}$ control system for fedbatch biochemical processes. Information Technology and Control. 2009. Vol. 38. No. 3. P. 225-231.

3. Jonelis K., Brazauskas K., Levišauskas D. A system for dissolved oxygen control in industrial aeration tank. Information Technology and Control. 2012. Vol. 41. No. 1. P. 46-52.

4. Kaminskas V., Liutkevičius R. Adaptive fuzzy control of pressure and level. Information Technology and Control. 2009. Vol. 38. No. 3. P. 232-236.

5. Koerfer R., Simutis R. Advanced process control for fluidized bed agglomeration. Information Technology and Control. 2008. Vol. 37. No. 4. P. 285-293.

6. Åström K. J., Wittenmark B. Computer-Controlled Systems: Theory and Design. New Jersey: Prentice Hall, 1997.

7. Bobál B., Böhm J., Fessl J., Macháček J. Digital Self-tuning Controllers. London: Springer-Verlag, 2005.

8. Liaučius G., Kaminskas V. Digital self-tuning PID control of pressure process. Proceedings of the 6th International Conference on Electrical and Control Technologies (ECT-2011), May 5-6, 2011, Kaunas, Lithuania. P. 109113.

9. Liaučius G., Kaminskas V., Liutkevičius R. Digital selftuning PID control of pressure plant with closed-loop optimization. Information Technology and Control. 2011. Vol. 40. No. 3. P. 202-209.
10. Ortega R., Kelly R. PID self-tuners. Some theoretical and practical aspects. IEEE Transactions of Industrial Electronics. 1984. Vol. 31. 1984. P. 332-338.

11. Kaminskas V. Dynamic System Identification via Discrete-time Observation: Part 1. Statistical Method Foundation. Estimation in Linear Systems. Vilnius: Mokslas Publishers, 1982 (in Russian).

12. Liaučius G., Kaminskas V. Closed-loop optimization algorithms in digital self-tuning PID control of pressure process. Proceedings of the 7th International Conference on Electrical and Control Technologies (ECT-2012), May 7-8, 2012, Kaunas, Lithuania. P. 25-29.

Gediminas Liaučius, Vytautas Kaminskas

\section{SLĖGIO PROCESO ADAPTYVUSIS SKAITMENINIS PID VALDYMAS}

\section{Santrauka}

Nagrinejjamas slëgio proceso adaptyvusis skaitmeninis valdymas panaudojant PID (proporcinius-integruojančius-diferencijuojančius) reguliatorius. Pasiūlytas valdymo sistemos uždarojo kontūro parametrų bei tolydinio signalo diskretizavimo periodo optimizavimo metodas. Eksperimentiškai parodyta, kad adaptyvusis PID valdymas su optimizavimu leidžia pagerinti slègio proceso valdymo kokybę.

Raktažodžiai: sleggio procesas, adaptyvusis skaitmeninis PID valdymas, uždarojo kontūro parametrai, diskretizavimo periodas, optimizavimas

\section{Гедиминас Ляучюс, Витаутас Каминскас}

\section{АДАПТИВНОЕ ЦИФРОВОЕ ПИД УПРАВЛЕНИЕ ПРОЦЕССОМ ДАВЛЕНИЯ}

\section{Резюме}

Рассматриваются вопросы адаптивного цифрового управления процессом давления с применением ПИД (пропорционально-интегрально-дифференциальных) регуляторов. Предложен метод оптимизации параметров замкнутого контура системы управления и периода дискретизации аналоговых сигналов. Экспериментально показано, что адаптивное ПИД управление с оптимизацией позволяет существенно увеличить качество управления процессом давления.

Ключевые слова: процесс давления, адаптивное цифровое ПИД управление, параметры замкнутого контура, период дискретизации, оптимизация 